\title{
Waste Paper Managment
}

\author{
Vijay Kumar, Shipra Gupta, Jasmeet Kalra, Brij Bhusan
}

\begin{abstract}
This manuscript investigates the waste paper management (WPM) of an educational Institute and aware the people about the importance of waste paper management and recycling of waste papers by multidimensional approach. The research assessed two multi long term plans, considering all recycling settings feasible for educational scenario. To complete that purpose, support for the collection of waste papers, final disposal its environmental and financial impact assessment concerning to transportation is also required. Results suggest that the quality of handmade papers is improved by doping some external materials in cellulose of waste papers. In this manuscript, flour of wheat is mixed in waste paper cellulose. The analysis of handmade paper is done by photometric test. It is found that at some percentages of doping of flour in waste paper pulp, the reflection properties of the paper is increased and surface of paper become smooth and hard. At some other percentages of doping, the papers are shown absorption properties. The traditional papers are manufactured in paper mills and the industries are one of the major source of responsible for air, water and land pollutions. By recycling of waste papers \& rags, the handmade papers are produced which may become the alternate of all types of papers. Recycling can help to keep the city clean. Papers are manufactured by wooden pulp and for this; the trees are cut from the forest. Recycling of waste papers is one solution to protect environment, deforestation, soil erosion, which can also lead to disaster like kedarnath disaster in 2013 and major threat to the atmosphere. Recycling of paper can also proved to be a new source of employment and can become a hot area for startups, as we have recently seen many various startups in the field of recycling, such as e-waste recycling, plactic recycling, etc.
\end{abstract}

Keywords: Recycling of waste papers, paper cellulose, rags, handmade papers and flour.

\section{INTRODUCTION}

Encouragement of people for recycling, can save the trees and environment. One-ton recycling of waste paper can save 30 equiliptis trees, 7000 gallons of water, 380 gallons of oil, 3.3 cubic yards of landfill space and $400 \mathrm{~kW}$ energy. The waste paper management in an educational Institute could be considered a viable solution for improving sustainability of environment. Solid waste management is an issue in terms of environment contamination and economic sustainability. Many methods have been introduced by the researchers as Sustainable Development Goals which is the sustainable life cycle of solid waste, giving attention to developing countries ${ }^{1}$. Sustainable waste management is a challenge for Municipal Corporation.

Revised Manuscript Received on April 25, 2019.

Vijay Kumar, Professor, Department of Physics, Graphic Era Hill University, Dehradun, India.

Shipra Gupta, Assistant Professor, Department of Commerce, Graphic Era Hill University, Dehradun, India.

Jasmeet Kalra. Assistant Professor, Department of Mechanical Engineering, Graphic Era Hill University, University, Dehradun, India.

Brij Bhusan, Professor, Department of Chemistry, Graphic Era Deemed to be University, Dehradun, India.
The development countries are facing the problems of Sustainable Waste Paper Management (SWPM). WPM is faced challenges of finance, culture, social and technological $^{2}$. The burning uncontrolled disposal is cause of $\mathrm{CO}, \mathrm{CO}_{2}, \mathrm{SO}$, $\mathrm{NO}$ and other emissions which affect the atmosphere directly ${ }^{3}$.

Dirtiness at many places of town and villages is a very serious problem in any country. The government is continuously inspiring the people for cleanliness. The recycling of waste papers is one of the best solutions for the waste management. The policies of other countries are different. solid waste policies are analyzed by the following countries Mozambique, Malaysia, India, Iran, China ${ }^{4}$, Investment costs, energy efficiency, pollutant emissions \& operations \&maintenance expenses etc. are required to analyze the use of integrated approaches of waste management system. In the past 40 years, worldwide, $400 \%$ consumption of paper has risen ${ }^{5} .35 \%$ of harvested trees are used only for manufacturing of the paper. This heavy consumption of the green trees becomes the reason of reduction of forest and greenery on the earth worldwide. After $40 \mathrm{~kg}$ recycling of waste paper, we can save the life of one eucalyptus tree ${ }^{2}$. Papers are used by all government and private offices, schools, Colleges, and the Universities. These used papers are thrown in dustbin and become waste. If these thrown waste papers are recycled, handmade papers can be produced for reuse and office use document files, notepads, soft notice boards, carry bags, visiting cards, wedding cards etc. may be manufactured ${ }^{6}$.

In Uttarakhand, no process of solid waste is followed while everyday this state is generated 1406 tones solid waste. Besides Arunachal Pradesh, it is the only state in the country to have this abysmal performance. Everyday our neighboring Himachal Pradesh is generated just 342 tons solid waste and $20 \%$ of it is processed by the state.

This has been revealed in a written reply submitted in the Rajya Sabha on March 8 by the Union ministry of housing and urban affairs. Out of 912 wards only 29 wards have the facilities of $100 \%$ segregation of waste at source. Furthermore, there are $21 \%$ wards $(71 \%)$ that still do not have $100 \%$ door-to-door collection of solid waste.

For achieving the target of $100 \%$ management of solid state, the country requires lot of time. Only $35 \%$ wards of country have $100 \%$ segregation of waste and only $70 \%$ wards have the facilities of door-to-door waste collection service.

\section{TO ENHANCE THE QUALITY OF HANDMADE PAPER:}

In present scenario the paper mill industry is continuously increasing their quantity to complete the demand of paper worldwide.

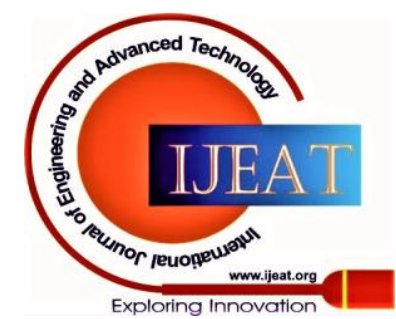


Due to this, the cutting of forest is continuously increasing and that's why the number of paper industries is also increasing every year. These industries are emitting harmful gases in environment which affect the health of public. Under these circumstances, many types of research and development (R\&D) are required in this field. The handmade paper may be used for many purposes. The papers may be modified as per the requirements. To produce many kinds of papers, rags and other ecofriendly materials in different ratio are used. Doping of different ratio in pulp of recycling of waste paper can change the properties of the papers.

In this manuscript, authors discussed one method of doping of external material (flour of wheat) with carton waste paper pulp in different ratios, and analyze the properties of handmade papers.

\section{MATERIAL AND METHOD}

In this manuscript, the handmade papers are prepared using waste carton packing papers with flour of wheat. To enhance the properties of recycled handmade papers, flour is used as doping materials with the pulp of waste carton papers. Carton papers are used by the Industry as a packing material and after unpackaging, it becomes totally useless. Different ratio of waste carton papers and flour are used and analyzed the density of materials by photometry test. In this test, the light is incident from different distances at different angles on the surface of recycled handmade papers and the intensity of reflected lights are analyzed by luxmeter. The distance of Luxmeter is kept equal to the distance of light source. The net weight of each sample is $20 \mathrm{gm}$. Each sample is prepared by doping of flour in pulp of waste papers and dried in sunlight. When paper becomes ready, it is passed through the rolling machine for its smooth surface. light is incident on the surface of sample from a distances of 5,10 and $15 \mathrm{~cm}$ and The reflected light from the surface is analyzed at angles of $10^{\circ}, 25^{\circ}, 40^{\circ}, 55^{\circ}$ and $70^{\circ}$ respectively. current waste flow and the analyzing has been applied after a field study for assessing current management issues by this method $^{8}$, which represent the baseline for the application of this research. In particular, the investigation is introduced due to the requirement to start a SG system in the city, for reducing environmental impacts and boosting sustainable development ${ }^{7}$. So, the aim is to build a waste management system according to the principle of the circular economy (CE) and the $3 \mathrm{R}$ (Reduce, reuse, and recycle) approach ${ }^{8}$, considering local characteristics. The MCDA is introduced with the analysis of the greenhouse gas emission due to MSW transport and final disposal, the assessment of the material recovery rate due to recycling and the cost economic due to the recovery of recyclable materials, the reduction of MSW transportation and waste inflow into the final disposal site ${ }^{9}$.

The ratio of cartoon waste papers and flour of wheat in samples of handmade papers are as: sample1 (19 gm waste cartoon papers (wcp)and 1 gm flour ), sample 2 (18 gm wcp and 2 gm flour), sample 3 (17 gm wcp and $3 \mathrm{gm}$ flour),sample 4 (16 gm wcp and $4 \mathrm{gm}$ flour),sample 2 (15 gm wcp and 5 gm flour),

\section{4. RESULTS AND DISCUSSION:}

When light is incident at $5 \mathrm{~cm}$ distance from the surface of sample no. 1 , the maximum \& minimum intensity of reflected light is get to be at $25^{\circ} \& 70^{\circ}$ respectively. It means if angle of incidence varies from $25^{\circ} \& 70^{\circ}$, the intensity of reflected light get reduced by $75.49 \%$. When distance of incident source increases $10 \mathrm{~cm}$ it becomes maximum at $10^{\circ}$ $\&$ minimum at $55^{\circ}$, the intensity is reduced to $24.5 \%$. At 15 $\mathrm{cm}$ distance of source, the intensity becomes maximum at $10^{\circ} \&$ minimum $40^{\circ}$ respectively and intensity is reduced to $26.9 \%$.

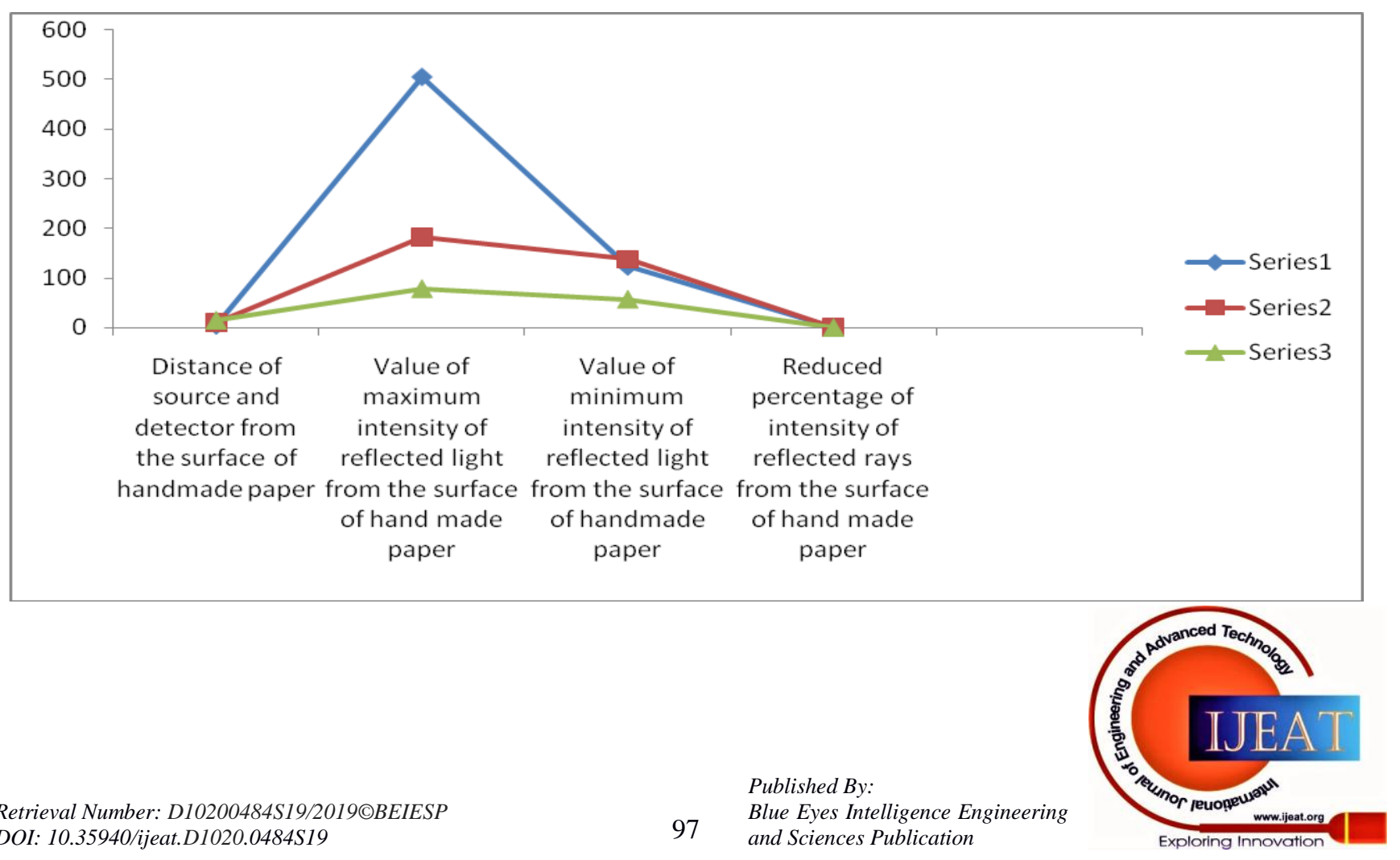


Fig

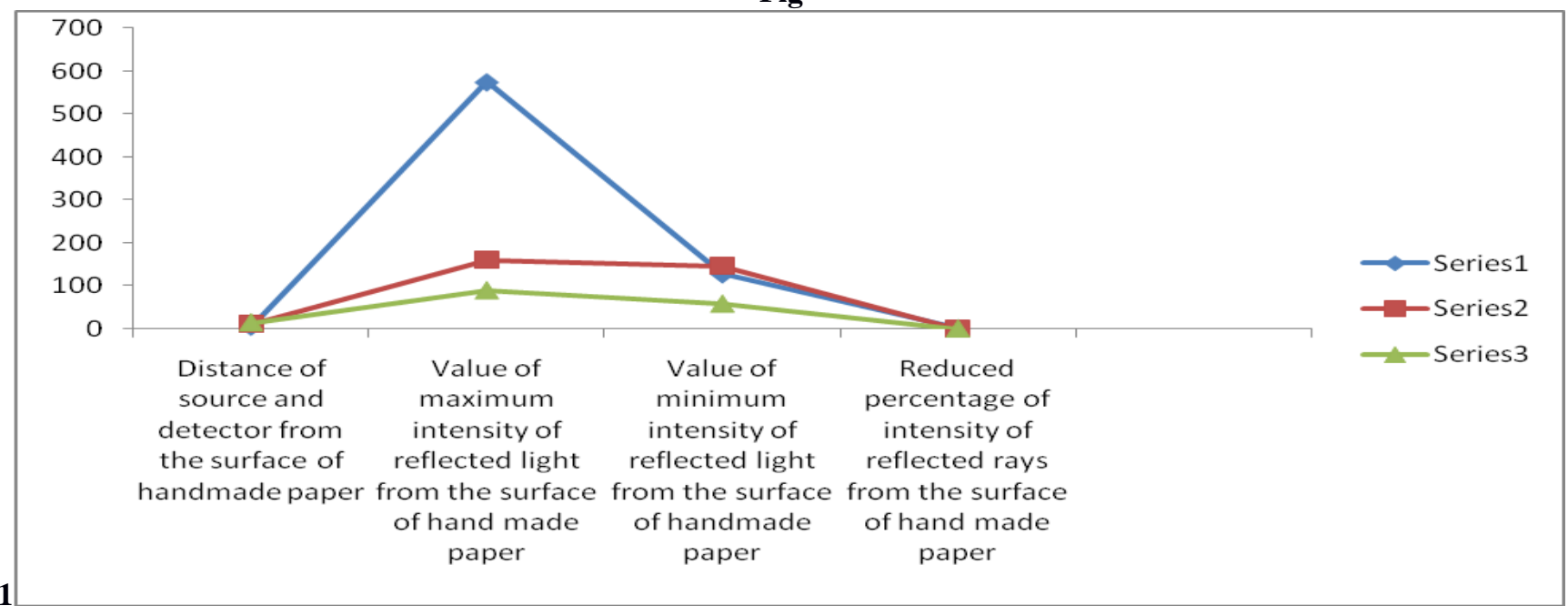

\section{Fig}

2

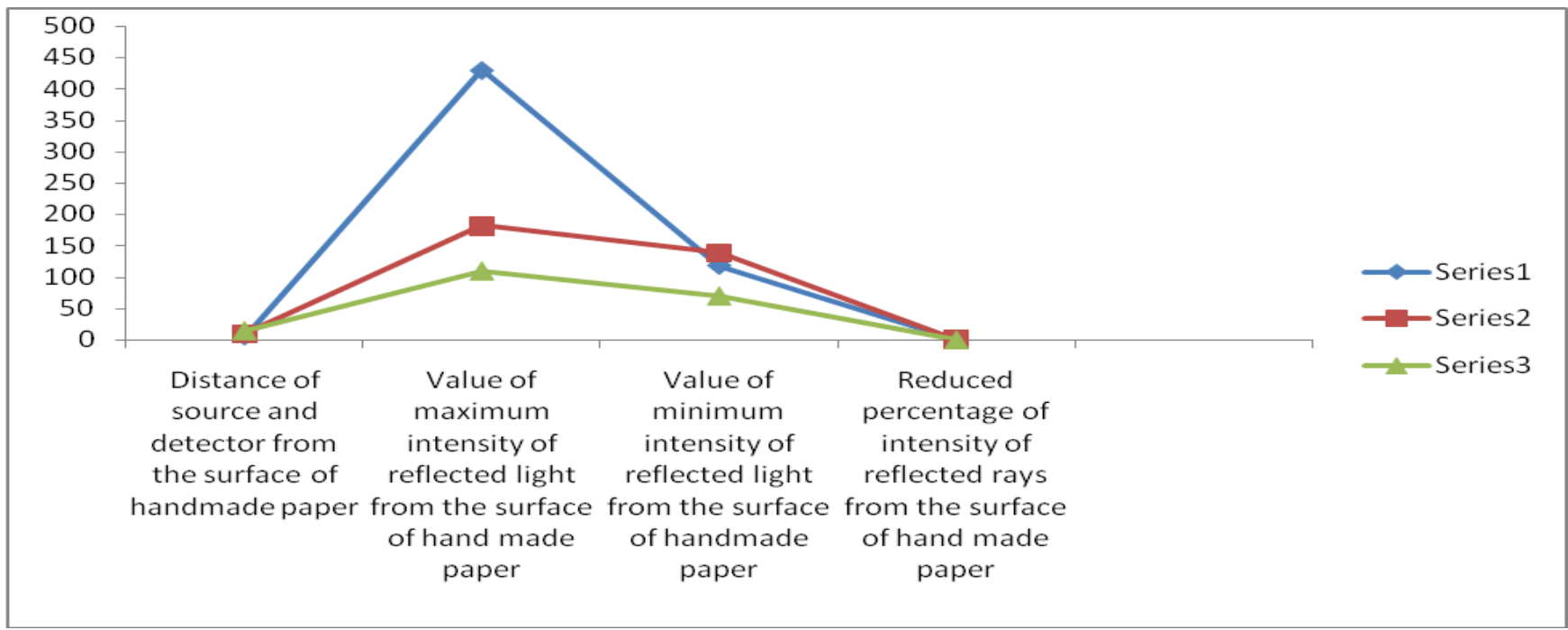

Fig 3

Fig 1 shows the variation between angle of reflected light and intensity of reflected light from the surface of paper.When surface of sample no. 2 is kept at $5 \mathrm{~cm}$ distance from the light source, the maximum and minimum intensity of reflected light is get to be at $25^{\circ} \& 70^{\circ}$ respectively. It means if angle of incidence varies from $25^{\circ} \& 70^{\circ}$, the intensity of reflected light get reduced by $77.91 \%$. When distance of incident source increases $10 \mathrm{~cm}$ it becomes maximum at $70^{\circ} \&$ minimum at $10^{\circ}$, the intensity is reduced to $8.7 \%$. At $15 \mathrm{~cm}$ distance of source, the intensity becomes maximum at $70^{\circ} \&$ minimum at $55^{\circ}$ respectively and intensity is reduced to $34.73 \%$.

Fig 2 shows the variation between angle of reflected light and intensity of reflected light from the surface of paper. The intensity curve of $5 \mathrm{~cm}$ distance intersect at one place only with the curve of $10 \mathrm{~cm}$ distance which represents that properties of this handmade paper remain same at this positions of source and observations. The curve of $10 \mathrm{~cm}$ and $15 \mathrm{~cm}$ does not intersect anywhere which represents at these two positions, there is no similarities in properties of the sample. In this observation, sample no. 2 is used in which $18 \mathrm{gm}$ carton waste paper and $2 \mathrm{gm}$ flour is used.

When surface of sample number 3 is kept at $5 \mathrm{~cm}$ from the light source, the maximum and minimum intensity of reflected light is get to be at $40^{\circ} \& 10^{\circ}$ respectively. It means if angle of incidence varies from $40^{\circ} \& 10^{\circ}$, the intensity of reflected light get reduced by $72.55 \%$. When distance of incident source increases $10 \mathrm{~cm}$ it becomes maximum at $70^{\circ} \&$ minimum at $10^{\circ}$, the intensity is reduced to $23.62 \%$. At $15 \mathrm{~cm}$ distance of source, the intensity becomes maximum at $70^{\circ} \&$ minimum $40^{\circ}$ respectively and intensity is reduced to $36.18 \%$.

Fig 3 shows the variation between angle of reflected light and intensity of reflected light from the surface of paper. The intensity curve of $5 \mathrm{~cm}$ distance intersect at two places with the curve of $10 \mathrm{~cm}$ distance which represents that properties of this handmade paper remain same at two positions of source and observations. The curve of $10 \mathrm{~cm}$ and $15 \mathrm{~cm}$ does not intersect anywhere which represents at these two positions, there is no similarities in properties of the sample. In this observation, sample no. 3 is used in which $17 \mathrm{gm}$ carton waste paper and $3 \mathrm{gm}$ flour is used.

The maximum and minimum intensity of reflected light is get to be at $25^{\circ} \& 70^{\circ}$ respectively when surface of sample 4 is kept at $5 \mathrm{~cm}$ from the light source, It means if angle of incidence varies from $25^{\circ} \&$

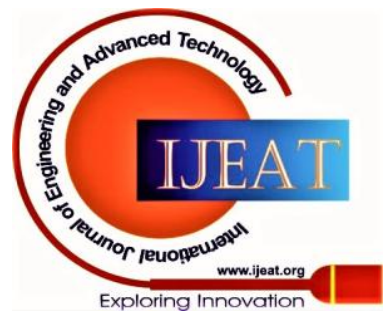


$70^{\circ}$, the intensity of reflected light get reduced by $58.03 \%$.

When distance of incident source increases $10 \mathrm{~cm}$ it becomes maximum at $70^{\circ} \&$ minimum at $10^{\circ}$, the intensity is reduced to $27.69 \%$. At $15 \mathrm{~cm}$ distance of source, the intensity becomes maximum at $70^{\circ} \&$ minimum $55^{\circ}$ respectively and intensity is reduced to $37.18 \%$

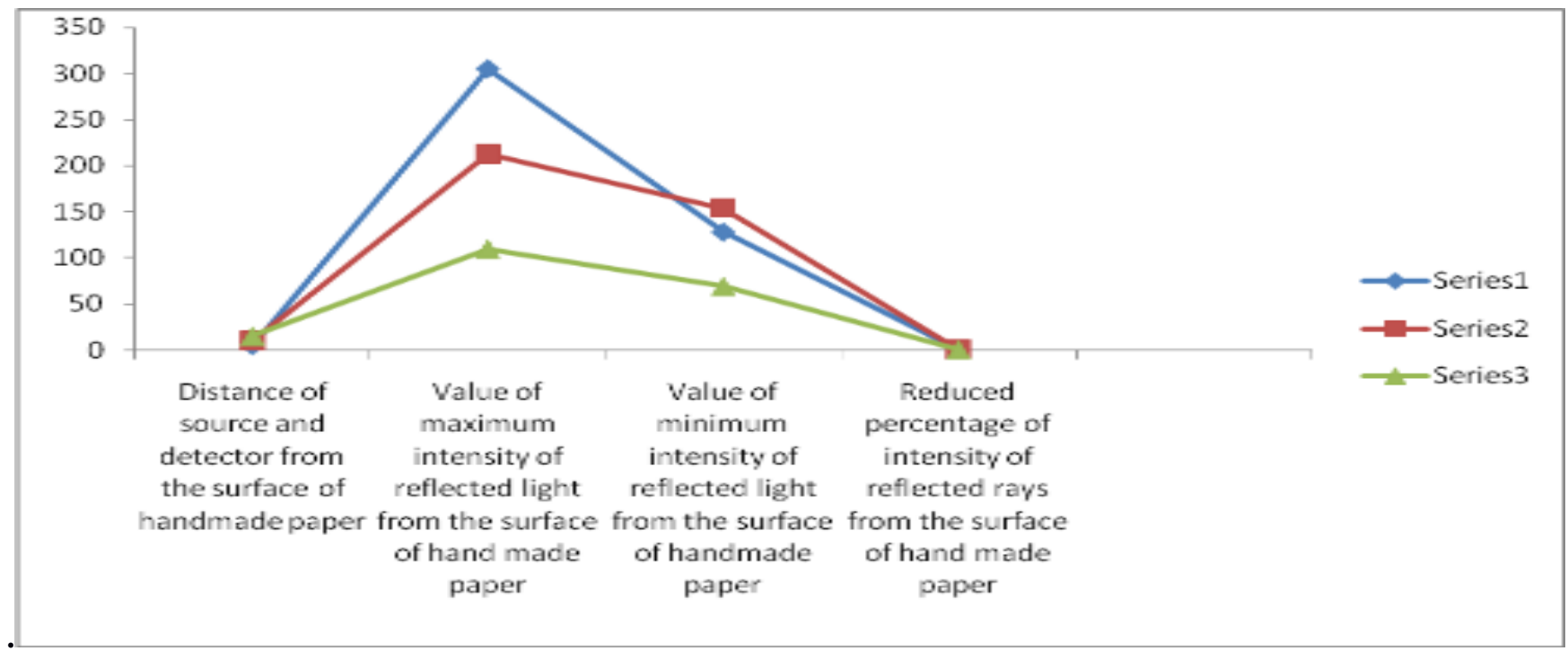

Fig 4

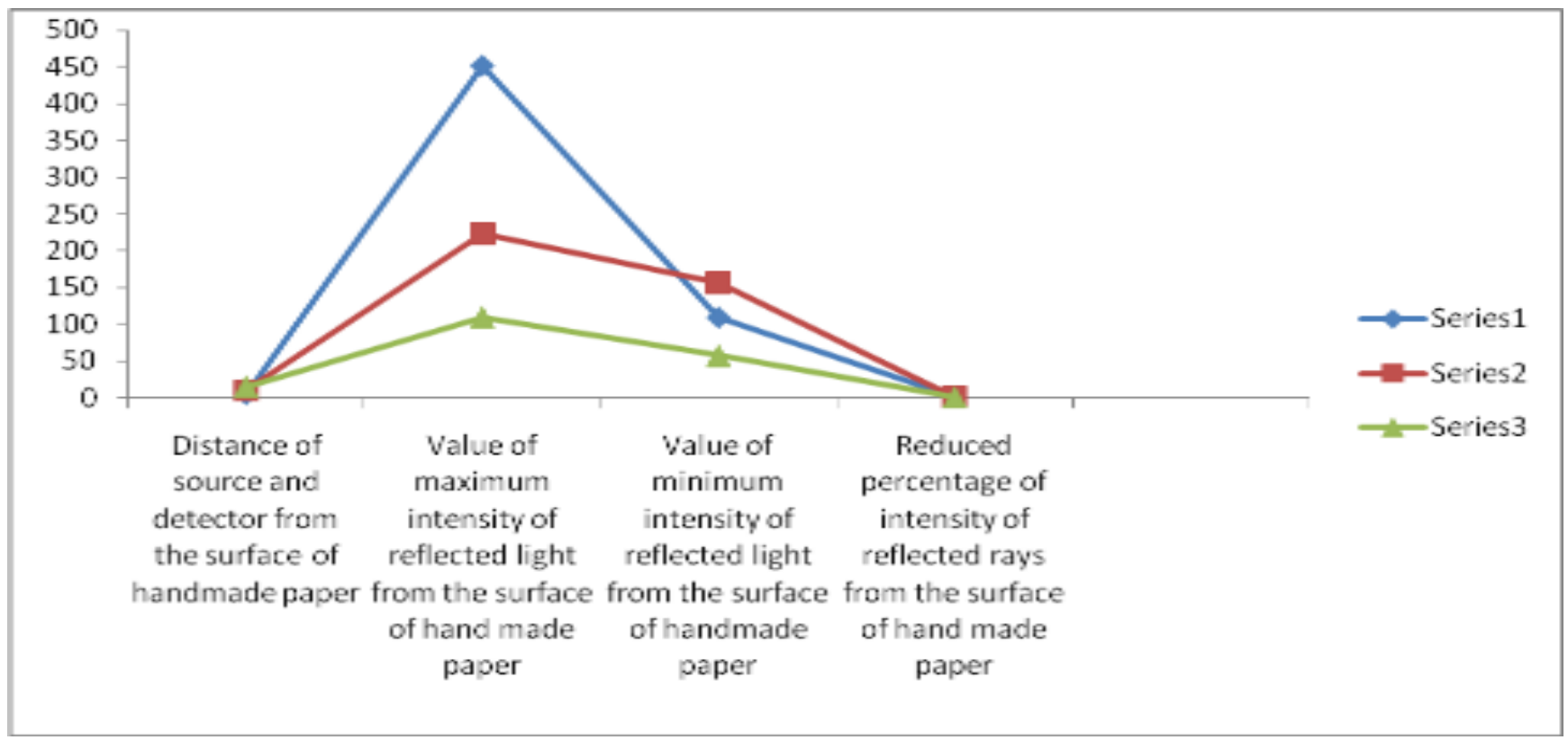

Fig 5

Fig 4 shows the variation between angle of reflected light and intensity of reflected light from the surface of paper. The intensity curve of $5 \mathrm{~cm}$ distance intersect at two places with the curve of $10 \mathrm{~cm}$ distance which represents that properties of this handmade paper sample remain same at these two positions of source and observations. The curve of $10 \mathrm{~cm}$ and $15 \mathrm{~cm}$ also intersect at one place, it means at these two positions properties of sample again remains same. In this observation, sample no. 4 is used in which 16 gm carton waste paper and $4 \mathrm{gm}$ flour is used.

The maximum and minimum intensity of reflected light is get to be at $40^{\circ} \& 70^{\circ}$ respectively when surface of sample 5 is kept at $5 \mathrm{~cm}$ from the light source, It means if angle of incidence varies from $40^{\circ} \& 70^{\circ}$, the intensity of reflected light get reduced by $75.83 \%$. When distance of incident source increases $10 \mathrm{~cm}$ it becomes maximum at $70^{\circ} \&$ minimum at $25^{\circ}$, the intensity is reduced to $29.91 \%$. At 15 $\mathrm{cm}$ distance of source, the intensity becomes maximum at $70^{\circ} \&$ minimum $40^{\circ}$ respectively and intensity is reduced to $47.88 \%$.

Fig 5 shows the variation between angle of reflected light and intensity of reflected light from the surface of paper. The intensity curve of $5 \mathrm{~cm}$ distance intersect at one place with the curve of $10 \mathrm{~cm}$ and at one place with the curve of $15 \mathrm{~cm}$ which represent that properties of this handmade paper sample remain same at one position at $10 \mathrm{~cm}$ and one position at $15 \mathrm{~cm}$ of source and luxmeter. In this observation, sample no. 5 is used in which 15 gm carton waste paper and $5 \mathrm{gm}$ flour is used.

Published By:

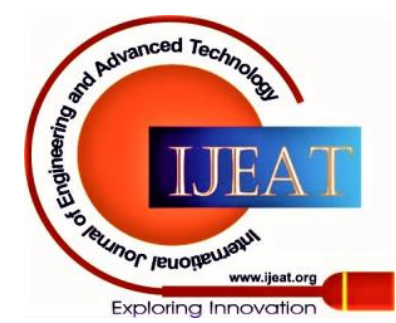




\section{CONCLUSION}

After above analysis, it is concluded that, some ration of flour of wheat can increase the hardness and some can increase the softness of the handmade papers. As the percentage of flour in waste cartoon papers are increased (5\% to $25 \%$ ), the absorption properties of the papers are also decreased.But as the percentage of the flour becomes $30 \%$, the absorption properties of the paper are increased.When the percentage of the flouris increased $35 \%$ \& $40 \%$, the absorption of light by handmade paper increases and after that decreases respectively.But as the percentage of flour becomes more than $40 \%$, the absorption of light by the handmade paper is decreased continuously. The handmade papers may be the alternate of any type of papers. If the amount of doping material (flour) is changed, the properties of the handmade papers are also changed. The reflected and absorption properties may be increased or decreased. These papers may be used to make product as carry bags, student examination pads, note pads, office files, soft notice boards etc. All the products save the life of trees and protect the environment.

\section{REFERENCES}

1. Aghajani Mir, M., TahereiGhazvinei, P., Sulaiman, N. M. N., Basri, N. E. A., Saheri, S., Mahmood, N. Z., Jahan, A., Begum, R. A., Aghamohammadi, N., 2016. Application of TOPSIS and VIKOR improved versions in a multi criteria decision analysis to develop an optimized municipal solid waste management model. J. Environ. Manag. 166, 109-115. https://doi.org/10.1016/j.jenman.2015.09.028.

2. Bahrani, S., Ebadi, T., Ehsani, H., Yousefi, H., Maknoon, R., 2016. Modeling landfill site selection by multi-criteria analysis of policy options for hydropower surplus utilization in paraguay. Energy Policy 108, 312-321. https://doi.org/101016/j.enpol.2017.06.003.

3. F. Navarro, R. Macro, A. G. P. Marcelo, G. G. L. Edith, V. Paolo and T. Vincenzo, 2019, How to improve recycling rate in developing big cities: An integrated approach for assessing municipal solid waste collection and treatment scenarios, Environment Development, 29, 94-110.

4. Vitorino deSouzaMelare, A.,Montengro Gonzalez, S., Faceil, K., Casedei, V., Technologies and decision support systems to aid solidwaste management: A systematic review. Waste Mang. 2017, 59, 567-584.

5. Wiedinmyer C., Yokelson R. J., Gullett B. K. Global emission of trace gases, particulate matter and hazardous air pollutants from open burning of domestic waste. Environ. Sci. Technol. 2014, 9523-9530.

6. Hubbe and Bowden, 2009 "Handmade paper, review,"BioResources, 4(4): 1736-1792.

7. Hubbe, M. A. 2007a. "Paper's resistance to wetting - A review of internal sizing chemicals and their effects," BioResources, 2(1), 106145.

8. Hubbe, M. A., Chen, H., and Heitmann, J. A.,2009. "Permeability reduction phenomena in packed beds, fiber mats, and wet webs of paper exposed to flow of liquids and suspensions: A review," BioResources, 4(1): 405-451.

9. Hubbe, M. A. 2006. "Bonding between cellulosic fibers in the absence and presence of dry-strength agents - A review,'BioResources,1 (2): 281-318. 